\title{
BMJ Open Gender differences between WOMAC index scores, health-related quality of life and physical performance in an elderly Taiwanese population with knee osteoarthritis
}

\author{
Wen-Hui Fang, ${ }^{1}$ Guo-Shu Huang, ${ }^{2}$ Hsien-Feng Chang, ${ }^{3}$ Ching-Yang Chen, ${ }^{4}$ \\ Chi-Yu Kang, ${ }^{5}$ Chih-Chien Wang, ${ }^{6}$ Chin Lin, ${ }^{7}$ Jia-Hwa Yang, ${ }^{7}$ Wen Su, ${ }^{8}$ \\ SenYeong Kao, ${ }^{3}$ Sui-Lung $\mathrm{Su}^{3}$
}

To cite: Fang $\mathrm{W}-\mathrm{H}$, Huang G-S, Chang H-F, et al. Gender differences between WOMAC index scores, healthrelated quality of life and physical performance in an elderly Taiwanese population with knee osteoarthritis. BMJ Open 2015;5:e008542. doi:10.1136/bmjopen-2015008542

\section{- Prepublication history} and additional material is available. To view please visit the journal (http://dx.doi.org/ 10.1136/bmjopen-2015008542)

Received 28 April 2015 Revised 19 August 2015 Accepted 21 August 2015

CrossMark

For numbered affiliations see end of article.

Correspondence to Dr Sui-Lung Su; a131419@gmail.com

\section{ABSTRACT}

Objective: To investigate the importance of the WOMAC index score, health-related quality of life and physical performance in each domain affected by knee osteoarthritis $(\mathrm{OA})$ and to identify gender differences in the importance of these domains and physical performances.

Material and methods: We performed a populationbased study for radiographic knee OA among participants aged more than 65 years. Demographic data were collected and anthropometric measurement, radiographic assessment, the WOMAC index score, the short-form 12 (SF-12), the Timed and Up to Go Test (TUGT) and the Five Times Sit to Stand Test (FTSST) were performed.

Result: There were 901 individuals (409 males and 492 females) aged $74.04 \pm 6.92$ (male: $76.35 \pm 7.33$; female: $72.12 \pm 5.92$ ) years included in this study. The WOMAC scores of participants with $\mathrm{OA}$ were higher than those without $O A$ in males and females (male: $11.97 \pm 15.79$ vs $8.23 \pm 12.84, p<0.001$; female: $10.61 \pm 14.97$ vs 7.59 $\pm 3.31, p=0.032$ ). The physical component summary (PCS) score was only significant in females with knee $0 A$ (62.14 \pm 24.66 vs $66.59 \pm 23.85, p=0.043)$, while the mental component summary (MCS) score was only significant in males with knee $0 A(78.02 \pm 18.59$ vs 81.98 $\pm 15.46, p=0.02)$. The TUGT and FTSST were not significant in individuals with and without $O A$ in males and females. Moreover, the multivariate results for the WOMAC score were significant for females (3.928 (95\% Cl 1.287 to 6.569), $p=0.004$ ).

Conclusions: The PCS domains of SF-12 and MCS domains of SF-12 are crucial in Taiwanese females and elderly males, respectively, with knee OA. Different evaluation and treatment strategies based on gender differences should be considered in elderly Taiwanese patients with knee OA to improve their quality of life.

\section{INTRODUCTION}

Knee osteoarthritis (OA) is characterised by the degeneration of articular cartilage,

\section{Strengths and limitations of this study}

- To explore the gender difference in the effect on the quality of life in people who suffered from knee osteoarthritis $(\mathrm{OA})$ in different cultures and environments.

- Furthermore, the results could be used to design a strategy to increase the quality of life of elderly Taiwanese patients with knee $0 A$.

- This study utilised a self-reported diseasespecific and health-related questionnaire and a physical performance test to assess quality of life.

- The cross-sectional design of this study precluded any causal inference.

- This sample had a limited age range.

morphological changes in the subchondral bone and damage to the surrounding soft tissue. $^{1}{ }^{2}$ These structural changes lead to joint pain, quadriceps muscle weakness, reduced range of motion and joint instability. $^{3}{ }^{4}$ As a result, knee $\mathrm{OA}$ is the most common form of chronic joint disease and the leading cause of lower limb disability in elderly populations. ${ }^{3-7}$

The limitations in activity caused by OA seriously affect social relationships, body image, emotional well-being and quality of life (QOL), particularly at an advanced age. ${ }^{8} 9$

During the past few decades, many instruments have become available to measure QOL. These QOL scales are either generic or disease-specific and some have been developed as clinical tools for outcome measurements in patients with OA. ${ }^{10} 11$

The Western Ontario and McMaster (WOMAC) index is one of the most widely used outcome measures for this purpose. WOMAC is a disease-specific instrument for 
measuring the level of pain, joint stiffness and functional ability and was applied for the evaluation of knee and/ or hip OA by Bellamy et al. ${ }^{12} 13$

Health-related QOL (HRQOL) is a concept which represents an individual's perceived health status and overall physical and mental well-being. Among the generic scales, the Medical Outcome Study Short Form-12 (SF-12) has been widely used to measure HRQOL in patients with OA. ${ }^{14}$

Although self-reported measures of function are often primary end points in clinical outcome studies, growing evidence has shown that objective performance-based assessments, such as the Timed and Up to Go Test (TUGT) and the Five Times Sit to Stand Test (FTSST), could demonstrate different aspects of clinical function. ${ }^{15-18}$

Some studies have shown that performance-based assessments identify limitations in physical function earlier compared with self-reported assessments. ${ }^{17} \quad 19$ Performance-based assessments are required to obtain a more complete picture of the functional limitations in populations with knee OA. ${ }^{20}{ }^{21}$ Therefore, both performance-based and self-reported outcome measures should be included as part of a comprehensive patient profile to accurately assess the multiple domains of physical function and disability in elderly populations with OA.

Studies in the USA and Japan have suggested that gender difference plays an important role in $\mathrm{OA}$ and HRQOL. $^{22}{ }^{23}$ It has been suggested that ethnicity also affects the relationship between QOL, functional disability and OA. ${ }^{24-26}$ However, studies that explore the population of Taiwan are lacking. Therefore, we hypothesised that the relationship between WOMAC, HRQOL, physical performance and knee OA would be affected by culture, environment and ethnicity. The purpose of this study was to identify the role of gender differences in QOL measures and physical performance in an elderly Taiwanese population with knee OA.

\section{MATERIALS AND METHODS \\ Participants}

This population-based study enrolled 901 participants (409 males and 492 females) and consisted of both healthy individuals and patients aged 65 years and older (mean (SD) age $=74.04$ (6.92) years), who received Taipei city senior medical check-ups between March 2010 and July 2011 at the Tri-Service General Hospital (TSGH), a medical teaching hospital of the National Defence Medical Centre in Taipei, Taiwan. The Taipei city senior medical check-up programme is a governmental welfare programme provided to people who are aged 65 or older and who have been registered residents in Taipei city for more than 1 year.

We explored the associated information at the Health Management Centre of TSGH while the participants received the check-up programme. All participants who were willing to join this study after full explanation by investigators were enrolled. Patients who had undergone knee surgery, such as total knee arthroplasty, were excluded. This study was approved by the TSGH Institutional Review Board (TSGH-100-05-023). All participants provided written informed consent. The demographic data included age, gender, body mass index (BMI: $\mathrm{kg} / \mathrm{m}^{2}$ ), occupation before retirement, years of formal education and weekly exercise level. We defined one instance of exercise as more than $30 \mathrm{~min}$ of moderate intensity physical activity. ${ }^{27}$

\section{Measures \\ Radiographic assessment}

All participants underwent radiographic examination of both knees using anteroposterior and lateral views with weight-bearing and foot-map positioning. Knee radiographs were read and scored by two readers, including a radiologist and a rheumatologist blinded to the patients' clinical information, using the Kellgren/Lawrence (KL) grading system. ${ }^{28}$ In KL grading, radiographs are scored from 0 to 4 . If the results yielded different K-L grades, we recruited a third interpreter to confirm the final grade. For patients with different K-L grades in each knee, the more advanced grade was taken for evaluation. We used a radiographic grade of $\geq 2$ on the Kellgren/ Lawrence scale to define knee OA.

\section{Instruments}

Western Ontario and McMaster Index

The WOMAC osteoarthritis index is a disease-specific measure of health status. It provides information on clinically important, patient-relevant symptoms in the areas of pain, stiffness and physical function in patients with knee OA. ${ }^{29}$ WOMAC includes 5 items that measure pain, 2 items that measure stiffness and 17 items that measure physical function. We used the Likert version of the WOMAC, wherein each item is scored on a five-point scale. Scores for each scale are created by summing the points of the individual items. Higher scores represent worse health status. Both the reliability and validity of WOMAC have been established. ${ }^{12} 30$

\section{Short Form-12}

The SF-12 was used to assess the status of general physical health. It consists of 12 questions covering 8 health domains of physical functioning $(\mathrm{PF})$, social functioning $(\mathrm{SF})$, role-physical (RP), role-emotional (RE), mental health (ME), energy/vitality (VT), bodily pain (BP) and general health perception $(\mathrm{GH}){ }^{31}{ }^{32}$ The questions were combined, scored and weighted to create the physical component summary score (PCS) and mental component summary score (MCS) ((ranging from 0 (lowest level of health) to 100 (highest level of health)). The score of PCS is composed of PF, RP, BP and GH and the score of MCS is composed of SF, RE, ME and VT.

\section{Timed and Up to Go Test}

In this test, individuals are given verbal instructions to stand up from a chair with an armrest, walk $3 \mathrm{~m}$ as 
quickly and safely as possible, cross a line marked on the floor, turn around, walk back and sit down. The test includes the time it takes for the individual to get out of the chair after he/she is told to 'Go'. We defined times longer than $12 \mathrm{~s}$ as impaired lower extremity function. ${ }^{33} 34$

\section{Five Times Sit to Stand Test}

In this test, the patient sits with arms folded across the chest and with his/her back against a chair $(43 \mathrm{~cm}$ high and $47.5 \mathrm{~cm}$ deep). The participants were instructed to stand up fully between repetitions and not to touch the back of chair, using the standard instruction, "I want you to stand up and sit five times as quickly as you can, when I say 'Go'." Timing begins at 'Go' and ends when the buttocks touch the chair after the fifth repetition. We defined a time longer than $15 \mathrm{~s}$ to represent impaired lower extremity function. ${ }^{35-38}$

\section{Statistical analysis}

Categorical and continuous variables were presented as a number (proportion) and mean \pm SD. We used Student $\mathrm{t}$ test to compare the WOMAC index score, SF-12 domains, TUGT and FTSST between elderly Taiwanese patients with and without knee OA. We also stratified the results by gender and compared the above variables with Student t test.

To test the effect of each independent variable on each dependent variable, linear regression and logistic regression were used to test their effects. To determine the independent association of radiographic knee OA and physical performance with quality measures, we used multiple regression analysis with adjustment for age, BMI, education and exercise.

Statistical significance was set at a $\mathrm{p}$ value of $<0.05$. Data analyses were performed using the $\mathrm{R}$ statistical program (V.3.1.1).

\section{RESULTS}

Table 1 shows the characteristics of the participants in this study. There were 901 individuals (409 males and 492 females) aged $74.04 \pm 6.92$ years (male: $76.35 \pm 7.33$; female: 72.12 \pm 5.92 ). The mean BMI was 24.29, 24.38 and 24.22 in all individuals, males and females, respectively. The occupational profile, years of formal education and weekly exercise levels are also shown in table 1.

Table 2 shows the differences between participants with and without knee $\mathrm{OA}$ in QOL and performancebased assessment. The WOMAC scores in patients with knee OA were higher than in those without knee OA in terms of pain, stiffness, physical function and total scores. The SF-12 scores, including PCS and MCS, were lower in participants with knee OA compared with people without it. However, some subitems had no significant difference between participants with and without knee OA ( $p$ value of role-physical $=0.225$; $p$ value of general health $=0.139 ; p$ value of social functioning $=0.183$; and $p$ value of mental health $=0.328$ ) In addition, the differences between participants with and without knee OA were not marked for TUGT and FTSST.

Table 3 shows the difference between male participants with and without knee OA in QOL and performance-based assessment. The WOMAC scores in men with OA were higher than those in men without $\mathrm{OA}$ in terms of pain, stiffness and total scores, but not in physical function. The patients with OA had lower MCS scores on SF-12 than the patients without OA, but there was no marked difference between the two groups in PCS scores. Moreover, TUGT and FTSST showed no marked difference in physical performance between men with and without OA.

Table 4 shows the difference between female participants with and without knee OA in QOL and performance-based assessments. The WOMAC scores in

\begin{tabular}{llll}
\multicolumn{2}{l}{ Table 1 Characteristics of the participants and stratification by gender } & & Female \\
\hline Characteristic & Overall & Male & $492(54.6 \%)$ \\
\hline Number & 901 & $409(45.4 \%)$ & $72.12 \pm 5.92$ \\
Age, mean \pm SD & $74.04 \pm 6.92$ & $76.35 \pm 7.33$ & $24.22 \pm 3.50$ \\
BMI $\left(\mathrm{kg} / \mathrm{m}^{2}\right)$ & $24.29 \pm 3.25$ & $24.38 \pm 2.92$ & \\
Occupation & & & $230(46.7 \%)$ \\
$\quad$ White collar & $503(55.8 \%)$ & $273(66.7 \%)$ & $75(15.2 \%)$ \\
$\quad$ Blue collar & $203(22.5 \%)$ & $128(31.3 \%)$ & $187(38 \%)$ \\
$\quad$ Not working & $195(21.6 \%)$ & $8(2 \%)$ & $373(75.8 \%)$ \\
Years of formal education & & & $119(24.2 \%)$ \\
$\quad \leq 12$ years & $574(63.7 \%)$ & $201(49.1 \%)$ & \\
$>12$ years & $327(36.3 \%)$ & $208(50.9 \%)$ & $88(17.9 \%)$ \\
Weekly exercise level & & $49(12.0 \%)$ & $134(27.2 \%)$ \\
$\quad$ None & $137(15.2 \%)$ & $92(22.5 \%)$ & $270(54.9 \%)$ \\
$1-3$ times & $226(25.1 \%)$ & $268(65.5)$ &
\end{tabular}


Table 2 Difference of the WOMAC scores, SF-12 scores and physical performance between the participants with knee OA or without

\begin{tabular}{|c|c|c|c|}
\hline & $\begin{array}{l}\text { With OA } \\
\text { (mean } \pm S D) \\
N=460\end{array}$ & $\begin{array}{l}\text { Without OA } \\
\text { (mean } \pm S D \text { ) } \\
N=441\end{array}$ & p Value \\
\hline \multicolumn{4}{|l|}{ WOMAC } \\
\hline Pain & $2.60 \pm 3.57$ & $1.85 \pm 2.94$ & 0.001 \\
\hline Stiffness & $1.08 \pm 1.58$ & $0.74 \pm 1.39$ & 0.001 \\
\hline Physical function & $8.29 \pm 11.71$ & $5.74 \pm 9.57$ & 0.001 \\
\hline Total & $11.97 \pm 15.79$ & $8.23 \pm 12.84$ & $<0.001$ \\
\hline \multicolumn{4}{|l|}{ SF-12 } \\
\hline Physical functioning (PF) & $65.54 \pm 32.34$ & $71.88 \pm 30.94$ & 0.003 \\
\hline Role-physical (RP) & $62.39 \pm 46.43$ & $66.10 \pm 45.12$ & 0.225 \\
\hline Bodily pain (BP) & $86.47 \pm 20.30$ & $89.43 \pm 18.87$ & 0.024 \\
\hline General health (GH) & $48.65 \pm 29.39$ & $51.52 \pm 28.73$ & 0.139 \\
\hline Vitality (VT) & $63.65 \pm 27.39$ & $68.39 \pm 25.25$ & 0.007 \\
\hline Social functioning (SF) & $81.52 \pm 23.18$ & $83.50 \pm 21.42$ & 0.183 \\
\hline Role-emotional (RE) & $81.74 \pm 37.68$ & $86.39 \pm 32.28$ & 0.046 \\
\hline Mental health $(\mathrm{MH})$ & $78.33 \pm 18.80$ & $79.52 \pm 17.90$ & 0.328 \\
\hline \multicolumn{4}{|l|}{ SF-12 } \\
\hline PCS & $65.76 \pm 24.67$ & $69.73 \pm 23.69$ & 0.014 \\
\hline MCS & $76.31 \pm 19.60$ & $79.45 \pm 16.66$ & 0.010 \\
\hline TUGT (s) & $9.90 \pm 3.40$ & $9.45 \pm 4.50$ & 0.090 \\
\hline FTSST (s) & $13.77 \pm 5.67$ & $13.00 \pm 6.42$ & 0.060 \\
\hline
\end{tabular}

females with OA were higher than those without OA in terms of pain, stiffness, physical function and total scores. It is worth noting these different results in females. The PCS score of SF-12 was markedly different in females (participants with knee OA vs without knee
$\mathrm{OA}, \mathrm{p}=0.043$ ) compared with that in males (participants with knee OA vs without knee $\mathrm{OA}, \mathrm{p}=0.239)$. However, the MCS score was inversed. In addition, physical performance was not markedly different in TUGT and FTSST in women with and without OA.

Table 3 Difference of the WOMAC scores, SF-12 scores and physical performance between the male participants with knee OA or without

\begin{tabular}{|c|c|c|c|}
\hline & $\begin{array}{l}\text { With OA } \\
\text { (mean } \pm S D \text { ) } \\
\mathrm{N}=200\end{array}$ & $\begin{array}{l}\text { Without OA } \\
\text { (mean } \pm S D) \\
\mathrm{N}=209\end{array}$ & p Value \\
\hline Pain & $2.24 \pm 3.18$ & $1.53 \pm 2.97$ & 0.021 \\
\hline Stiffness & $0.93 \pm 1.40$ & $0.62 \pm 1.38$ & 0.026 \\
\hline Physical function & $7.40 \pm 11.46$ & $5.44 \pm 10.21$ & 0.062 \\
\hline \multicolumn{4}{|l|}{ SF-12 } \\
\hline Physical functioning (PF) & $70.25 \pm 31.84$ & $77.27 \pm 29.79$ & 0.022 \\
\hline Role-physical (RP) & $69.25 \pm 44.74$ & $70.33 \pm 42.80$ & 0.802 \\
\hline Bodily pain (BP) & $89.33 \pm 17.68$ & $89.93 \pm 19.41$ & 0.743 \\
\hline General health $(\mathrm{GH})$ & $53.10 \pm 28.51$ & $55.36 \pm 28.63$ & 0.425 \\
\hline Vitality (VT) & $65.80 \pm 26.34$ & $71.10 \pm 23.27$ & 0.031 \\
\hline PCS & $70.48 \pm 23.94$ & $73.22 \pm 23.07$ & 0.239 \\
\hline MCS & $78.02 \pm 18.59$ & $81.98 \pm 15.46$ & 0.020 \\
\hline TUGT (s) & $9.51 \pm 3.26$ & $9.20 \pm 3.08$ & 0.334 \\
\hline FTSST (s) & $13.27 \pm 5.16$ & $12.47 \pm 6.42$ & 0.177 \\
\hline
\end{tabular}


Table 4 Difference of the WOMAC scores, SF-12 scores and physical performance between the female participants with knee OA or without

\begin{tabular}{|c|c|c|c|}
\hline & $\begin{array}{l}\text { With OA } \\
\text { (mean } \pm S D) \\
N=260\end{array}$ & $\begin{array}{l}\text { Without OA } \\
\text { (mean } \pm \text { SD) } \\
\mathrm{N}=232\end{array}$ & p Value \\
\hline \multicolumn{4}{|l|}{ WOMAC } \\
\hline Pain & $2.88 \pm 3.83$ & $2.14 \pm 2.88$ & 0.015 \\
\hline Stiffness & $1.19 \pm 1.70$ & $1.84 \pm 1.39$ & 0.013 \\
\hline Physical function & $8.94 \pm 11.87$ & $6.00 \pm 8.98$ & 0.002 \\
\hline Total & $13.01 \pm 16.35$ & $8.99 \pm 12.39$ & 0.002 \\
\hline \multicolumn{4}{|l|}{ SF-12 } \\
\hline Physical functioning (PF) & $61.92 \pm 32.32$ & $67.03 \pm 31.23$ & 0.076 \\
\hline Role-physical (RP) & $57.11 \pm 47.09$ & $62.28 \pm 46.87$ & 0.224 \\
\hline Bodily pain (BP) & $84.27 \pm 21.88$ & $88.99 \pm 18.40$ & 0.010 \\
\hline General health $(\mathrm{GH})$ & $45.23 \pm 29.65$ & $48.06 \pm 28.44$ & 0.282 \\
\hline Vitality (VT) & $62.00 \pm 28.10$ & $65.95 \pm 26.73$ & 0.112 \\
\hline Social functioning (SF) & $78.94 \pm 24.09$ & $81.47 \pm 22.10$ & 0.229 \\
\hline Role-emotional (RE) & $82.88 \pm 36.57$ & $83.84 \pm 35.55$ & 0.770 \\
\hline Mental health (MH) & $76.15 \pm 19.03$ & $77.46 \pm 17.95$ & 0.436 \\
\hline \multicolumn{4}{|l|}{ SF-12 } \\
\hline PCS & $62.14 \pm 24.66$ & $66.59 \pm 23.85$ & 0.043 \\
\hline MCS & $75.00 \pm 20.28$ & $77.18 \pm 17.39$ & 0.203 \\
\hline TUGT (s) & $10.20 \pm 3.48$ & $9.66 \pm 5.47$ & 0.195 \\
\hline FTSST (s) & $14.16 \pm 6.02$ & $13.46 \pm 6.39$ & 0.221 \\
\hline
\end{tabular}

The results of sex-specific analysis show the same results as displayed in tables 3 and 4. The PCS score of SF-12 was markedly higher in females without OA, but there was no marked difference in males. In contrast, the MCS score of SF-12 was markedly higher in males without OA, but there was no marked difference in females. The TUGT and FTSST were categorised into two groups based on the timing cut-off points as follows: $12 \mathrm{~s}$ for TUGT and $15 \mathrm{~s}$ for FTSST. In addition, we analysed the association between physical-based performance tests and QOL measures. These associations were very strong in males and females (all $\mathrm{p}$ values were less than 0.001, please see online supplementary tables S1-S3). The impact factors analysis of WOMAC, PCS, MCS, TUGT and FTSST are shown in online supplementary tables S4-S8, respectively.

We also checked the difference in WOMAC, SF-12 score and physical performance between females and males with knee OA. The PCS domain of females with knee OA had markedly lower scores than that of males with knee OA $(p \leq 0.001)$. The proportion of females with knee OA with an FTSST longer than $15 \mathrm{~s}$ was higher than that of males with knee OA $(p=0.015)$. Furthermore, the WOMAC and MCS scores in females with knee $\mathrm{OA}$ were lower than those in males with knee OA, but no statistical significance was shown in these two variables between females and males with knee OA. The proportion of TUGT longer than $12 \mathrm{~s}$ in females with knee OA was greater than that in males with knee OA; however, there was no statistical significance observed.
The multivariate models are shown in table 5. After adjusting for age, BMI, education and exercise, the patients with OA had no marked difference compared with individuals without OA on PCS, MCS, TUGT and FTSST. However, the total WOMAC scores were markedly different between females with and without $\mathrm{OA}$ $(\mathrm{p}=0.004)$, but not in males $(\mathrm{p}=0.220)$.

\section{DISCUSSION}

This study demonstrated a gender difference in WOMAC index scores (a disease-specific scale), SF-12 (an alternative form of health-related QOL measures) and physical-based performance in an elderly Taiwanese population with knee OA. The present study shows that elderly Taiwanese females with $\mathrm{KL} \geq 2$ have significantly lower PCS scores than those with $\mathrm{KL}=0$ or 1 (difference between them on PCS: -4.46). Samsa et a $\ell^{39}$ elucidated that the Minimally Clinically Important Difference (MCID) for SF-36 is typically in the range of 3-5 points. In other words, a difference of 3 points or more in SF-36 scores is clinically important. In this study, the difference in PCS scores and similar MCID thresholds between females with $\mathrm{KL} \geq 2$ and those with $\mathrm{KL}=0$ or 1 was 4.46, implying that PCS domains play a clinically important role in females with knee OA.

Muraki et $a l^{23}$ showed that participants with $\mathrm{KL}=3$ or 4 had significantly lower PCS scores than those with $\mathrm{KL}=0$, 1 or 2. Our data also demonstrated this trend. However, their study showed that the MCS score was higher with $\mathrm{KL}=3$ or 4 than that with $\mathrm{KL}=0$ or 1 in men and 
Table 5 The change by OA in multiple regression on WOMAC score, SF-12 score and performance-based assessment

\begin{tabular}{|c|c|c|c|c|c|c|}
\hline & \multicolumn{3}{|l|}{ Men } & \multicolumn{3}{|l|}{ Women } \\
\hline & $\bar{\beta}$ & $95 \% \mathrm{Cl}$ & p Value & $\bar{\beta}$ & $95 \% \mathrm{Cl}$ & p Value \\
\hline WOMAC* $^{*}$ & 1.738 & $(-1.041$ to 4.516$)$ & 0.220 & 3.928 & (1.287 to 6.569 ) & 0.004 \\
\hline $\mathrm{PCS}^{\star}$ & -0.881 & $(-5.390$ to 3.628$)$ & 0.702 & -3.264 & $(-7.660$ to 1.132$)$ & 0.146 \\
\hline $\mathrm{MCS}^{*}$ & -3.115 & ( -6.413 to 0.183$)$ & 0.064 & -1.627 & $(-5.113$ to 1.860$)$ & 0.361 \\
\hline TUGT (12 cut)† & -0.575 & $(-1.234$ to 0.084$)$ & 0.087 & 0.323 & $(-0.211$ to 0.857$)$ & 0.236 \\
\hline FTSST (15 cut)† & 0.024 & $(-0.497$ to 0.546$)$ & 0.927 & 0.122 & $(-0.289$ to 0.533$)$ & 0.560 \\
\hline
\end{tabular}

All results were adjusted by age, BMI, education and exercise.

${ }^{*}$ Result of linear regression.

tResult of logistic regression.

BMI, body mass index; FTSST, Five Times Sit to Stand Test; MCS, mental component summary; PCS, physical component summary;

TUGT, Timed and Up to Go Test; WOMAC, Western Ontario and McMaster index.

women. ${ }^{23}$ Muraki et $a l^{40}$ stated that the phenomenon was due to a so-called 'disability paradox'. Our study illustrated that the MCS score was lower in patients with $\mathrm{KL}=2$ or more relative to those with $\mathrm{KL}=1$ or less, especially in males, consistent with another Chinese hospitalbased study from Woo $e t a l^{8}$ The absence of a so-called 'disability paradox' in Chinese and Taiwanese populations further supports the effects of different cultures and genders on HRQOL, even in the same disease. Further investigation is needed to address this topic.

Logerstedt et $a t^{22}$ showed the same results for PCS scores (males: 38.18-53.31=-15.13; females: 34.39$56.43=-21.94)$. Although the effects of OA on PCS in females and MCS in males were not marked after adjusting for age, BMI, education and exercise, their difference was still greater than MCID (PCS in females: -3.264; MCS in males: -3.115). Moreover, the difference between females with and without $\mathrm{OA}$ was marked on WOMAC, but the difference between males with and without OA was not marked on WOMAC. Since the three components of WOMAC were directly associated with PCS, this result confirmed the role of OA on PCS in females.

The major impact of OA on PCS in females was bodily pain $(p=0.010)$. Moreover, the role of OA on bodily pain in males was not significant $(\mathrm{p}=0.743)$. This suggests that while the decline in physical function itself affects elderly Taiwanese women, elderly Taiwanese men do not think that they are physically affected. Kim et $a l^{41}$ also found that knee pain had a greater impact in women with knee OA compared with men. Many studies indicated that women have a lower pain threshold and a lower tolerance to pain than men in the laboratory situation. ${ }^{42-44}$ Furthermore, previous research has stated that women are vulnerable to developing and sustaining musculoskeletal pain conditions. ${ }^{45}{ }^{46}$ Therefore, major preventive strategies in females with OA should focus on the reduction of bodily pain.

Another interesting contrast between males and females can be observed in tables 3 and 4 . While a significant difference in MCS exists between males with and without OA $(\mathrm{p}=0.020)$, there was no such difference in females $(p=0.203)$. Specifically, the difference between males with $\mathrm{OA}$ and without $\mathrm{OA}$ comes from two subitems: vitality $(\mathrm{p}=0.031)$ and role-emotional $(p=0.008)$. However, there was no significance in physical performance (TUGT and FTSST tests) in males with or without knee OA. This suggests that it is psychological stress rather than the decline in the physical performance that affects the mental health of elderly Taiwanese males.

Regarding the differences between females and males with knee OA, the PCS domains and FTSST longer than $15 \mathrm{~s}$ were statistically significant. Females with knee OA had lower PCS scores than males with knee OA, consistent with other studies from Logerstedt et al (34.39 vs 38.18) and Muraki et al (43.8 vs 44.7). This finding suggested that females with knee OA had more pain, greater pain sensitivity, poorer performance and worse perceived function than males with knee OA. Females with knee OA had a greater proportion of FTSST longer than $15 \mathrm{~s}$ compared with males with knee OA, but there was no significant difference in TUGT longer than $12 \mathrm{~s}$ between females and males with knee OA. Logerstedt et al reported a markedly significant difference in TUGT between females and males with knee OA, but there was no significant difference in TUGT between females and males with knee $\mathrm{OA}$ in our study. The differences in these study groups may have contributed part of this difference, because the knee $\mathrm{OA}$ in the patients in our study might have been less severe compared with that in their patients. Females with early knee OA are more sensitive in FTSST. We suggested that FTSST could be used in early knee OA participants to compare gender differences.

On the basis of the results in tables 3 and 4, with regard to patients with $\mathrm{OA}$, we need to pay attention to mental health in males and physical function in females. Therefore, different strategies may be required in the evaluation and management of males and females with knee OA to improve their quality of life.

With increasing age, physical-based performance and QOL measures worsened. This observation was similar to those of previous studies and also clearly illustrates that increasing age is a significant risk factor in people with knee OA. ${ }^{47-50}$ Jarvholm et al proposed a "non- 
linear' relationship between age and the incidence of knee OA. There is a sharp rise in the incidence of knee OA between the ages of 50 and 75 , but only a limited rise above age $75 .^{51}$

We found that physical-based performance and QOL measures deteriorated with reduced frequency of daily exercise. This finding is similar to those of White $e t a l^{52}$ who proposed that higher levels of walking activity could protect against the development of functional limitations in people with or at risk of knee OA. In other words, the prevention of a sedentary lifestyle and encouragement of increased daily exercise in elderly populations are helpful in maintaining physical function and QOL.

The univariable analysis showed a significant association between HRQOL and knee OA. Although the result of multivariable analysis presented non-significant results, these results showed the same trend with univariable results. The non-significance may have been due to the small sample size, as statistical power is reduced by increased degrees of freedom in the model. However, the absolute changes of PCS in females and MCS in males were both greater than MCID. Thus, we considered this to still have clinical significance.

\section{Limitations}

There are several limitations to our study. First, this is a population-based cross-sectional study; therefore, it is difficult to demonstrate a causal relationship. Further follow-up on this subject may elicit clear causal relationships. Second, other weight-bearing OAs, such as OA of the hip, were not included in the analysis, although these conditions also affect QOL and physical performance. However, knee OA remains the leading cause of OA. Third, the participants in our study are all community-dwelling elderly people who are eligible to receive Taipei city senior medical check-ups. Moreover, the contents of announcement for participants included the impact of knee OA. This group may represent part of the general population, but extrapolation should be limited. Fourth, all the participants who walk into a hospital to receive medical check-ups have relatively higher physical performance and QOL measures than those who stay at home and do not receive medical check-ups. Therefore, QOL measures and physical performance in patients with OA may have been overestimated in our study population, and consequently any differences between them may be underestimated. However, this did not affect our conclusions.

\section{CONCLUSION}

This cross-sectional study indicated that elderly Taiwanese females with knee OA had relatively lower scores in the PCS domain of SF-12 than those without knee OA. At the same time, elderly Taiwanese males with knee OA had relatively lower scores in the MCS domain of SF-12 than those without knee OA. Both genders with OA of the knee had higher WOMAC index scores than those without knee OA.

It is worth noting that different strategies may be required in the management of males and females with $\mathrm{OA}$, with the major objective of the management of mental health in males and physical function in females.

\section{Author affiliations}

${ }^{1}$ Department of Family and Community Medicine, Tri-Service General Hospital, National Defense Medical Center, Taipei, Taiwan, ROC

${ }^{2}$ Department of Radiology, Tri-Service General Hospital, National Defense Medical Center, Taipei, Taiwan, ROC

${ }^{3}$ School of Public Health, National Defense Medical Center, Taipei, Taiwan, $\mathrm{ROC}$

${ }^{4}$ Division of Radiology, National Defense Medical Center Tri-Service General Hospital Songshan Branch, Taipei, Taiwan, ROC

${ }^{5}$ Department of Aviation Medicine and Physical examination, National Defense Medical Center Tri-Service General Hospital Songshan Branch, Taipei, Taiwan, ROC

${ }^{6}$ Department of Orthopedics, Tri-Service General Hospital, National Defense Medical Center, Taipei, Taiwan, ROC

${ }^{7}$ Graduate Institute of Life Sciences, National Defense Medical Center, Taipei, Taiwan, ROC

${ }^{8}$ Department of Nursing, Chang Gung University of Science and Technology, Taoyuan, Taiwan, ROC

Contributors W-HF and S-LS conceived and designed the experiments. W-HF and S-LS performed the experiments. W-HF and CL analysed the data. W-HF and C-CW contributed reagents/materials/analysis tools. W-HF and S-LS wrote the paper. G-SH, C-YC, C-YK, J-HY, WS and SYK were responsible for critical review and comments. S-LS and H-FC were responsible for modifying the manuscript.

Funding This research received no specific grant from any funding agency in the public, commercial or not-for-profit sectors.

Competing interests None declared.

Ethics approval Tri-Service General Hospital IRB.

Provenance and peer review Not commissioned; externally peer reviewed.

Data sharing statement The raw data can be obtained from the corresponding author on request by email: a131419@gmail.com

Open Access This is an Open Access article distributed in accordance with the Creative Commons Attribution Non Commercial (CC BY-NC 4.0) license, which permits others to distribute, remix, adapt, build upon this work noncommercially, and license their derivative works on different terms, provided the original work is properly cited and the use is non-commercial. See: http:// creativecommons.org/licenses/by-nc/4.0/

\section{REFERENCES}

1. Felson DT, Lawrence RC, Dieppe PA, et al. Osteoarthritis: new insights. Part 1: the disease and its risk factors. Ann Intern Med 2000;133:635-46.

2. Ciombor DM, Aaron RK, Wang S, et al. Modification of osteoarthritis by pulsed electromagnetic field-a morphological study. Osteoarthritis Cartilage 2003;11:455-62.

3. Urwin M, Symmons D, Allison T, et al. Estimating the burden of musculoskeletal disorders in the community: the comparative prevalence of symptoms at different anatomical sites, and the relation to social deprivation. Ann Rheum Dis 1998;57:649-55.

4. Guccione AA, Felson DT, Anderson JJ, et al. The effects of specific medical conditions on the functional limitations of elders in the Framingham Study. Am J Public Health 1994;84:351-8.

5. Felson DT, Zhang Y. An update on the epidemiology of knee and hip osteoarthritis with a view to prevention. Arthritis Rheum 1998;41:1343-55.

6. Zhang Y, Jordan JM. Epidemiology of osteoarthritis. Clin Geriatr Med 2010;26:355-69.

7. Zhang $\mathrm{Y}, \mathrm{Xu} \mathrm{L}, \mathrm{Nevitt} \mathrm{MC}$, et al. Comparison of the prevalence of knee osteoarthritis between the elderly Chinese population in Beijing 
and whites in the United States: the Beijing Osteoarthritis Study. Arthritis Rheum 2001:44:2065-71.

8. Woo J, Lau E, Lee P, et al. Impact of osteoarthritis on quality of life in a Hong Kong Chinese population. J Rheumatol 2004;31:2433-8.

9. Arden N, Nevitt MC. Osteoarthritis: epidemiology. Best Pract Res Clin Rheumatol 2006;20:3-25.

10. Lequesne MG, Mery C, Samson M, et al. Indexes of severity for osteoarthritis of the hip and knee. Validation-value in comparison with other assessment tests. Scand J Rheumatol Suppl 1987;65:85-9.

11. Wright JG, Young NL. The patient-specific index: asking patients what they want. J Bone Joint Surg Am 1997;79:974-83.

12. Bellamy N, Buchanan WW, Goldsmith $\mathrm{CH}$, et al. Validation study of WOMAC: a health status instrument for measuring clinically important patient relevant outcomes to antirheumatic drug therapy in patients with osteoarthritis of the hip or knee. J Rheumatol 1988;15:1833-40.

13. Bellamy N, Buchanan WW. A preliminary evaluation of the dimensionality and clinical importance of pain and disability in osteoarthritis of the hip and knee. Clin Rheumatol 1986;5:231-41.

14. Busija L, Pausenberger E, Haines TP, et al. Adult measures of general health and health-related quality of life: Medical Outcomes Study Short Form 36-Item (SF-36) and Short Form 12-Item (SF-12) Health Surveys, Nottingham Health Profile (NHP), Sickness Impact Profile (SIP), Medical Outcomes Study Short Form 6D (SF-6D), Health Utilities Index Mark 3 (HUI3), Quality of Well-Being Scale (QWB), and Assessment of Quality of Life (AQoL). Arthritis Care Res (Hoboken) 2011;63(Suppl 11):S383-412.

15. Cress ME, Schechtman KB, Mulrow CD, et al. Relationship between physical performance and self-perceived physical function. $J \mathrm{Am}$ Geriatr Soc 1995;43:93-101.

16. Elam JT, Graney MJ, Beaver T, et al. Comparison of subjective ratings of function with observed functional ability of frail older persons. Am J Public Health 1991;81:1127-30.

17. Rozzini R, Frisoni GB, Ferrucci L, et al. The effect of chronic diseases on physical function. Comparison between activities of daily living scales and the physical performance test. Age Ageing 1997;26:281-7.

18. Sager MA, Dunham NC, Schwantes A, et al. Measurement of activities of daily living in hospitalized elderly: a comparison of self-report and performance-based methods. J Am Geriatr Soc 1992;40:457-62.

19. Brach JS, VanSwearingen JM, Newman AB, et al. Identifying early decline of physical function in community-dwelling older women: performance-based and self-report measures. Phys Ther 2002;82:320-8.

20. Stratford PW, Kennedy DM. Performance measures were necessary to obtain a complete picture of osteoarthritic patients. J Clin Epidemiol 2006;59:160-7.

21. Mizner RL, Petterson SC, Clements KE, et al. Measuring functional improvement after total knee arthroplasty requires both performance-based and patient-report assessments: a longitudinal analysis of outcomes. J Arthroplasty 2011;26:728-37.

22. Logerstedt DS, Zeni J Jr, Snyder-Mackler L. Sex differences in patients with different stages of knee osteoarthritis. Arch Phys Med Rehabil 2014:95:2376-81.

23. Muraki S, Akune T, Oka $\mathrm{H}$, et al. Association of radiographic and symptomatic knee osteoarthritis with health-related quality of life in a population-based cohort study in Japan: the ROAD study. Osteoarthritis Cartilage 2010;18:1227-34.

24. Ibrahim SA, Burant CJ, Siminoff LA, et al. Self-assessed global quality of life: a comparison between African-American and white older patients with arthritis. J Clin Epidemiol 2002;55:512-17.

25. Burns R, Graney MJ, Lummus AC, et al. Differences of self-reported osteoarthritis disability and race. J Natl Med Assoc 2007:99:1046-51.

26. Allen KD. Racial and ethnic disparities in osteoarthritis phenotypes. Curr Opin Rheumatol 2010;22:528-32.

27. Committee PAGA. Physical activity guidelines advisory committee report, 2008. Washington DC: US Department of Health and Human Services, 2008:A1-H14.

28. Kellgren JH, Lawrence JS. Radiological assessment of rheumatoid arthritis. Ann Rheum Dis 1957;16:485-93.
29. Mcconnell S, Kolopack P, Davis AM. The Western Ontario and McMaster Universities Osteoarthritis Index (WOMAC): a review of its utility and measurement properties. Arthritis Rheum 2001;45:453-61.

30. Xie F, Li S-C, Goeree R, et al. Validation of Chinese Western Ontario and McMaster Universities Osteoarthritis Index (WOMAC) in patients scheduled for total knee replacement. Qual Life Res 2008;17:595-601.

31. Ware J Jr, Kosinski M, Keller SD. A 12-Item Short-Form Health Survey: construction of scales and preliminary tests of reliability and validity. Med Care 1996;34:220-33.

32. Lam CL, Tse EY, Gandek B. Is the standard SF-12 health survey valid and equivalent for a Chinese population? Qual Life Res 2005; 14:539-47.

33. Bischoff HA, Stähelin HB, Monsch AU, et al. Identifying a cut-off point for normal mobility: a comparison of the timed 'up and go' test in community-dwelling and institutionalised elderly women. Age Ageing 2003;32:315-20.

34. Podsiadlo D, Richardson S. The timed "Up \& Go": a test of basic functional mobility for frail elderly persons. J Am Geriatr Soc 1991;39:142-8.

35. Whitney SL, Wrisley DM, Marchetti GF, et al. Clinical measurement of sit-to-stand performance in people with balance disorders: validity of data for the Five-Times-Sit-to-Stand Test. Phys Ther 2005;85:1034-45.

36. Buatois S, Perret-Guillaume C, Gueguen R, et al. A simple clinical scale to stratify risk of recurrent falls in community-dwelling adults aged 65 years and older. Phys Ther 2010;90:550-60.

37. Buatois $\mathrm{S}$, Miljkovic D, Manckoundia $\mathrm{P}$, et al. Five times sit to stand test is a predictor of recurrent falls in healthy community-living subjects aged 65 and older. J Am Geriatr Soc 2008;56:1575-7.

38. Christiansen CL, Stevens-Lapsley JE. Weight-bearing asymmetry in relation to measures of impairment and functional mobility for people with knee osteoarthritis. Arch Phys Med Rehabil 2010;91:1524-8.

39. Samsa G, Edelman D, Rothman ML, et al. Determining clinically important differences in health status measures: a general approach with illustration to the Health Utilities Index Mark II. Pharmacoeconomics 1999;15:141-55.

40. Albrecht GL, Devlieger PJ. The disability paradox: high quality of life against all odds. Soc Sci Med 1999;48:977-88.

41. Kim IJ, Kim HA, Seo Y-I, et al. Prevalence of knee pain and its influence on quality of life and physical function in the Korean elderly population: a community based cross-sectional study. J Korean Med Sci 2011;26:1140-6.

42. Fillingim RB. Sex, gender, and pain: women and men really are different. Curr Rev Pain 2000;4:24-30.

43. Riley JL III, Robinson ME, Wise EA, et al. Sex differences in the perception of noxious experimental stimuli: a meta-analysis. Pain 1998;74:181-7.

44. Sarlani E, Greenspan JD. Gender differences in temporal summation of mechanically evoked pain. Pain 2002;97:163-9.

45. Rollman GB, Lautenbacher S. Sex differences in musculoskeletal pain. Clin J Pain 2001:17:20-4.

46. Cairns BE, Gazerani P. Sex-related differences in pain. Maturitas 2009;63:292-6.

47. Jinks $\mathrm{C}$, Jordan KP, Blagojevic M, et al. Predictors of onset and progression of knee pain in adults living in the community. A prospective study. Rheumatology (Oxford) 2008;47:368-74.

48. Hochberg MC, Lethbridge-Cejku M, Tobin JD. Bone mineral density and osteoarthritis: data from the Baltimore Longitudinal Study of Aging. Osteoarthritis Cartilage 2004;12(Suppl A):S45-8.

49. Hart DJ, Doyle DV, Spector TD. Incidence and risk factors for radiographic knee osteoarthritis in middle-aged women: the Chingford Study. Arthritis Rheum 1999;42:17-24.

50. Lachance L, Sowers MF, Jamadar D, et al. The natural history of emergent osteoarthritis of the knee in women. Osteoarthritis Cartilage 2002;10:849-54.

51. Jarvholm B, Lewold S, Malchau $\mathrm{H}$, et al. Age, bodyweight, smoking habits and the risk of severe osteoarthritis in the hip and knee in men. Eur J Epidemiol 2005;20:537-42.

52. White DK, Tudor-Locke C, Zhang Y, et al. Daily walking and the risk of incident functional limitation in knee osteoarthritis: an observational study. Arthritis Care Res (Hoboken) 2014;66:1328-36. 